\title{
Binginering Jourtilal

\section{Effects of Reactor Loading and Solvent Addition on Catalyst-Free Glycerolysis of Palm Oil}

\author{
Ittirit Phichaion ${ }^{1, a}$, Ruengwit Sawangkaew ${ }^{2, b}$, Winatta Sakdasri $^{3, c}$, \\ and Somkiat Ngamprasertsith ${ }^{1,4, \mathrm{~d}, *}$
}

\author{
1 Fuels Research Center, Department of Chemical Technology, Faculty of Science, Chulalongkorn \\ University, Pathumwan, Bangkok 10330, Thailand \\ 2 The Institute of Biotechnology and Genetic Engineering, Chulalongkorn University, 254 Institute \\ Building 3, Phayathai Road, Pathumwan, Bangkok 10330, Thailand \\ 3 Program of Food Process Engineering, Faculty of Food-Industry, King Mongkut's Institute of \\ Technology Ladkrabang, Bangkok 10520, Thailand \\ 4 Centre of Excellent in Petrochemicals and Material Technology, Chulalongkorn University, Soi Chula \\ 12, Phayathai Road, Pathumwan, Bangkok 10330, Thailand \\ E-mail: aittirit.un@gmail.com, brueangwit.S@chula.ac.th, cwinatta.sa@kmitl.ac.th, \\ d, ${ }^{*}$ somkiat.n@chula.ac.th
}

\begin{abstract}
Glycerol is a by-product of biodiesel production. Every three moles of biodiesel produced, glycerol is released in one mole, which is around $10 \mathrm{wt.} \%$ of the total products. The crude glycerol from supercritical transesterification has a higher purity than that from alkaline transesterification. Monoglyceride is an anionic surfactant widely used in many applications. In this work, the glycerolysis reaction of palm oil and glycerol was studied using isopropanol as the solvent. The investigated important parameters in this study were reaction time in range of 30-150 minutes, reactor loading in range of 40-80 \%, and molar ratio of isopropanol to glycerol to palm oil in range of 0-30. The glycerol to palm oil molar ratio was constant at 5 to 1 . The results showed that parameters affected conversions and yields were reactor loading and solvent addition. The highest monoglyceride yield, $37.4 \%$, was obtained at $260{ }^{\circ} \mathrm{C}$ in 150 minutes and $40 \%$ of reactor loading. Molar ratio of glycerol to palm oil to isopropanol is 5:1:15. A central composite design (CCD) of 48 experiments investigated the effects on monoglyceride content $(\% \mathrm{MG})$ of temperature $(220$ to $260{ }^{\circ} \mathrm{C}$ ), reaction duration (30 to $150 \mathrm{~min}$ ), and molar ratio of IPA to palm oil (0:1 to 30:1). The \%MG was substantially and statistically significantly enhanced $(\mathrm{p}<0.0001)$ at higher temperatures and longer reaction duration. An analysis of variance confirmed that the molar ratio of IPA to palm oil had a much less significant effect $(\mathrm{p}=0.0255)$ on $\% \mathrm{MG}$. The crude glycerol obtained from a biodiesel production plant was compared with pure glycerol at the optimal condition. A $\% \mathrm{MG}$ of $46.58 \%$ was observed using crude glycerol as reactant because of the yield-limiting effects of water in crude glycerol.
\end{abstract}

Keywords: Glycerolysis, palm oil, glycerol, isopropanol.

ENGINEERING JOURNAL Volume 25 Issue 4

Received 4 December 2020

Accepted 29 December 2020

Published 30 April 2021

Online at https://engj.org/

DOI:10.4186/ej.2021.25.4.69 


\section{Introduction}

The fast growth in biodiesel production lead to excess of glycerol the main by product in this process. The transesterification process release biodiesel and glycerol at a molar ratio of 3:1. Between 2008 and 2012, glycerol production around the world increased by $9.3 \%$ per year, and the growth will estimate to be 3.5\% per year in 2025 . Glycerol is generated $\sim 10 \%$ by weight of biodiesel. Because rapidly grows of biodiesel production worldwide, the amount of glycerol in the world market is oversupplying nowadays.

The humectant properties of glycerol have long been and utilized in sweets, cakes, meats, and cheeses. In addition, glycerol has been used as solvent, sweetener and preservative in beverages and foods. Also, using glycerol to give the flavor and color in foods and soft drinks [1,2]. However, the degree of purity is the restricted usability of glycerol.

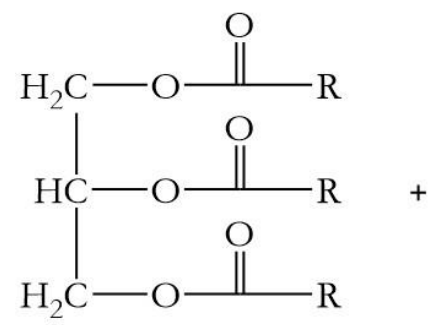

Triglyceride Catalyst<smiles>[R]C(=O)OCC(O)CO</smiles>

\section{Monoglyceride (major)}

Fig 1. Glycerolysis reaction between triglyceride and glycerol.

Conversion of glycerol to monoglyceride is an option to utilize glycerol as bio-based feedstock to solve the oversupply problem. Monoglyceride has many applications in cosmetics, pharmaceuticals, and food industries as surfactants. The glycerolysis of triglyceride (TG) with glycerol is the process that produced monoglycerides
(MG) and their derivatives as illustrated in Fig. 1. Monoglyceride is a raw material in various applications because of their emulsifying properties [3]. The optimal condition for monoglyceride production as found in the literatures is illustrated in Table 1.

The feedstocks for monoglyceride production are triglyceride, fatty acids, and fatty acid methyl esters. Using methyl ester as feedstock generates methanol as byproduct that is not suitable for food and cosmetic application. The basic catalysts, $\mathrm{KOH}$, and $\mathrm{Ca}(\mathrm{OH})_{2}$, are conventionally used in this process. Enzymatic and ionic liquid were reported as alternative catalysts that provide the high \%MG. The production of monoglyceride conducts with solvent or without solvent systems. Recently, the non-catalytic processes, using acetone and isopropanol (IPA) as solvents, were reported with the competitive \%MG.

The typically glycerolysis process is carries out at high temperature $\left(220-260{ }^{\circ} \mathrm{C}\right)$, with an alkali catalyst, pressurized under nitrogen atmosphere. The major drawback of using alkali catalyst in glycerolysis reduction is the presence of free fatty acids (FFA), which would result in the formation of metallic soap, leading to flavor and odor troubles when blend in food products [4].

To avoid such problems, isopropanol under subcritical condition was employed as solvent for the glycerolysis of palm oil without the use of conventional catalyst. According to Liu et. al, the authors demonstrated that isopropanol was the most effective solvent in glycerolysis reaction when compared to methanol and ethanol [4]. Even though three lower alcohols could reduce viscosities of reactant components, isopropanol provided the highest yield of monoglyceride. Apart from the highest yield obtained, isopropanol does not occur the side reaction while the others (methanol and ethanol) generate fatty acid ester, which is an unwanted by-product. Therefore, the objective of this study is to investigate the monoglyceride production from palm oil and glycerol in non-catalytic and solvent-free system, comparing to the IPA adding system. The glycerol conversion was measured for screening the suitable reactor loading and volume of solvent at constant temperature $\left(260{ }^{\circ} \mathrm{C}\right)$ in 30 90 minutes.

\section{Materials and methods}

\subsection{Materials}

The n-heptane and IPA were purchased from Fischer Chemical. High-purity (99\%) reagents, including tripalmitin, dipalmitin, monopalmitin, triolein, diolein, monoolein, palmitic acid, and oleic acid were supplied by Sigma-Aldirch. The refined palm oil was purchased from Morakot Industries Public Co., Ltd. The average molecular weight of palm oil was 840 as describe in our previous work [12]. The crude glycerol sample and its certificate of analysis were donated from Bangchak Biofuel Co., Ltd. 
Table 1 Optimal condition for monoglyceride production as reported in the literatures.

\begin{tabular}{|c|c|c|c|c|c|c|}
\hline \multirow[b]{2}{*}{ Feedstock } & \multirow[b]{2}{*}{ Catalyst } & \multirow[b]{2}{*}{ Solvent } & \multicolumn{3}{|c|}{ Optimal condition } & \multirow[b]{2}{*}{$\% \mathrm{MG}$} \\
\hline & & & $\begin{array}{r}\text { Temperature } \\
\left({ }^{\circ} \mathrm{C}\right)\end{array}$ & $\begin{array}{r}\text { Time } \\
\text { (hr.) }\end{array}$ & $\begin{array}{r}\text { Molar ratio } \\
\text { (Feed:glycerol) }\end{array}$ & \\
\hline Olive oil [5] & $\begin{array}{r}\text { Immobilized } \\
\text { Lipase (Candida } \\
\text { rugose) }\end{array}$ & $\begin{array}{c}\text { Isopropanol/ } \\
\text { tert-butanol }\end{array}$ & 40 & 4 & $1: 2$ & 55.8 \\
\hline Palmitic acid [6] & Novozyme 435 & Act- $\mathrm{ECO}_{2}{ }^{\mathrm{b}}$ & 50 & 5 & $1: 3$ & 58.68 \\
\hline Soybean oil [7] & {$[\mathrm{Bmim}] \mathrm{Im}^{\mathrm{a}}$} & - & 200 & 3 & $1: 6$ & 69 \\
\hline Palm oil [8] & CuO-nano & - & 240 & 1 & $2: 1$ & 25 \\
\hline Palm oil [8] & $\begin{array}{r}\text { CuO-nano/ } \\
\mathrm{NaOH} 0.3 \mathrm{wt}^{0} \%\end{array}$ & - & 240 & 0.5 & $2: 1$ & $\sim 71$ \\
\hline Methyl oleate [9] & $\mathrm{MgO}$ & - & 250 & 2 & $1: 4.5$ & 77 \\
\hline Triglyceride [3] & $\mathrm{KOH}, \mathrm{Ca}(\mathrm{OH})_{2}$ & $\mathrm{~N} / \mathrm{R}$ & 255 & $\mathrm{~N} / \mathrm{R}$ & $\mathrm{N} / \mathrm{R}$ & 50 \\
\hline Canola oil [10] & - & $\begin{array}{r}\mathrm{CO}_{2} / \mathrm{N}_{2} / \mathrm{H}_{2} \mathrm{O} \\
4-8 \%(\mathrm{w} / \mathrm{w})\end{array}$ & 250 & $9-10$ & $1: 34$ & $66-71$ \\
\hline Corn oil [11] & $\begin{array}{r}0.1 \mathrm{wt}^{0} \% \mathrm{CaO}- \\
\mathrm{CeO}_{2}\end{array}$ & - & 200 & 1 & $1: 3$ & 90 \\
\hline Sunflower oil [4] & - & Acetone & 250 & 2 & $1: 5$ & 52 \\
\hline Triolein [3] & - & Isopropanol & 260 & 2.5 & $1: 5$ & 67.80 \\
\hline Triolein [3] & - & - & 260 & 1.5 & $1: 5$ & 44.45 \\
\hline Palm oil [4] & - & - & 240 & 1 & $2: 1$ & 5 \\
\hline
\end{tabular}

$\mathrm{N} / \mathrm{R}$ is not reported.

${ }^{a}$ [Bmim]Im is 1-Butyl-3-Methylimidazolium imidazolide.

b Act-ECO2 is acetone expanded carbon dioxide.

\subsection{Glycerolysis of Triglyceride (Palm Oil)}

Predetermined amounts of palm oil, glycerol and isopropanol were added into a batch reactor $(4.2 \mathrm{~mL})$ and placed in a high-temperature fluidized sand bath as show in Fig. 1. The temperature in the reactor was controlled to constant temperature at $260^{\circ} \mathrm{C}$ with heating time of 30 $150 \mathrm{~min}$. The reaction was carried out with constant shaking (60 times per min) by a mechanical arm during the experiment progress. After the reaction complete, the reactor was rapidly cooled in water bath and the product in the reactor was collected at room temperature. In case of IPA added, the IPA was evaporated in a water bath at $85^{\circ} \mathrm{C}$ for 8 hours before analysis.

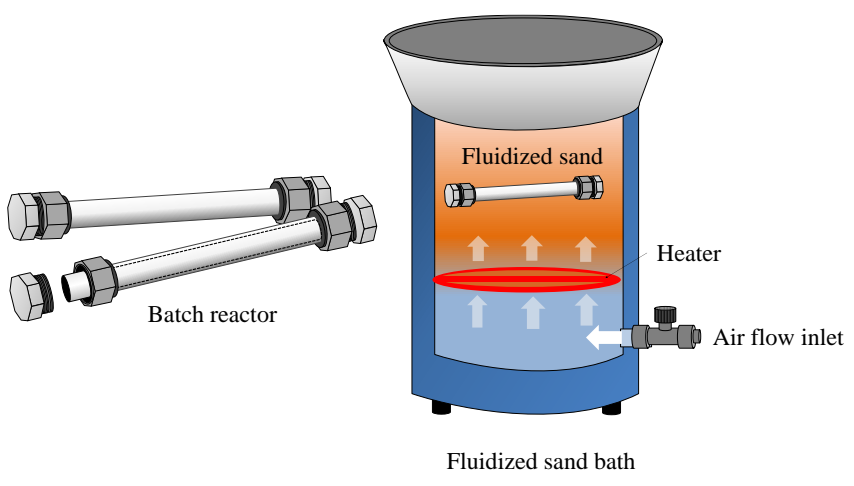

\subsection{GC Analysis}

Amounts of monoglyceride, diglyceride, and triglyceride were standardized by the external standard method. The samples diluted in ethanol were analyzed by gas chromatography (7890A, Agilent). The GC was equipped with capillary column MXT-WAX (30 m, 250 $\mu \mathrm{m}$ ID, $0.1 \mu \mathrm{m}$, Agilent Technologies, Inc.). The column initial temperature is $50{ }^{\circ} \mathrm{C}$, and the final constant temperature is $370{ }^{\circ} \mathrm{C}$. Both injector and flame ionization detector (FID) were set at $380{ }^{\circ} \mathrm{C}$. Glycerol conversion was calculated using Eq. (1).

$$
\text { Conversion }(\%)=\left(1-\frac{\text { Glycerol }_{\text {final }}}{\text { Glycerol }_{\text {initial }}}\right) \times 100 \%
$$

\subsection{GC-MS Analysis}

The sample was qualitatively analyzed by GC-MS (Shimudzu, model QP2010) to identify the fatty acid esters. The analytical conditions were reported in detail elsewhere [13]. In brief, the capillary column, J\&W Scientific, model DB-5ms $(30 \mathrm{~m} \times 0.25 \mu \mathrm{m} \times 0.25 \mathrm{~mm})$ was employed. The column oven was held at $50{ }^{\circ} \mathrm{C}$ for 5 $\mathrm{min}$, and then increased to $200{ }^{\circ} \mathrm{C}$ at $15{ }^{\circ} \mathrm{C} / \mathrm{min}$. The molecular weight scan range was $50-850 \mathrm{~m} / \mathrm{z}$. Injection

Fig. 2. The fluidized sand bath and the tube batch reactor. 
port and interface temperature were set at $200{ }^{\circ} \mathrm{C}$ and 230 ${ }^{\circ} \mathrm{C}$, respectively.

\subsection{Experimental Design}

To estimate the effects of temperature, reaction time, and molar ratio of reactants, triplicate central composite design (CCD), with an overall experiment of 48 runs, was employed to investigate the effects of the parameters shown in Table 2. The parameters and levels were selected to lie within ranges similar to those reported in studies of non-catalytic systems [4, 5]. To minimize uncontrolled factors, all experiments were conducted in random order, as shown in Table 3 .

Table 2. The selected parameters and levels for the CCD.

\begin{tabular}{rrrrrr}
\hline \multirow{2}{*}{ Factors } & \multirow{2}{*}{ Parameter } & \multirow{2}{*}{ Unit } & \multicolumn{4}{c}{ Levels } \\
\cline { 4 - 6 } & & & -1 & 0 & 1 \\
\hline $\mathrm{A}$ & Temperature & ${ }^{\circ} \mathrm{C}$ & 220 & 240 & 260 \\
$\mathrm{~B}$ & Reaction time & $\min$ & 30 & 90 & 150 \\
$\mathrm{C}$ & Isopropanol & & 0 & 15 & 30 \\
\hline
\end{tabular}

The CCD experimental data were used to develop a polynomial equation that correlates \%monoglyceride content $(\% \mathrm{MG}), \%$ diglyceride content $(\% \mathrm{DG}), \%$ fatty acid content $(\% \mathrm{FA})$, and $\%$ triglyceride content $(\% \mathrm{TG})$ as the responses. Equation (2) shows the general form of the second-order polynomial equation [18]:

$$
y=\beta_{0}+\sum_{(j=1)}^{k} \beta_{j} X_{j}+\sum_{(i<j)} \sum \beta_{i j} X_{i} X_{j}+\sum_{(j=1)}^{k} \beta_{j j} X_{j}^{2}+\varepsilon
$$

where $\mathrm{y}$ is the value of the response, and $X j$ and $X i X j$ are the main effects and interaction effects, respectively. $\beta_{0}$ is the overall mean. $\beta_{j}, \beta_{j j}$, and $\beta_{i j}$ are the coefficients of linear, quadratic, and interaction effects, respectively. $\varepsilon$ is random error.

\section{Results and Discussion}

\subsection{Effects of Reaction Time}

A monoglyceride yield (MG Yield) of $0.1 \%$ was observed at reaction time of 30 minutes as can be seen in Fig. 3.

The glycerolysis reaction at reaction time of 90 and 150 min produced the higher MG yield. Notes that a reaction time of 30 minutes is too short for the glycerolysis of palm oil. Similar to those reported in literatures $[4,5$, 14], for catalyst-free glycerolysis of oils were similarly process, which required reaction time up to 45 minutes. It was reported that the glycerolysis of triolein in noncatalytic solvent-free system has monoglyceride content of $44.45 \pm 0.35 \%[3]$.
Table 3. Experimental data for the central composite design (CCD) and results.

\begin{tabular}{|c|c|c|c|c|c|}
\hline $\begin{array}{l}\text { Run } \\
\text { order }\end{array}$ & $\begin{array}{r}\text { Temp. } \\
\left({ }^{\circ} \mathrm{C}\right)\end{array}$ & $\begin{array}{r}\text { Reaction } \\
\text { time } \\
(\mathrm{min})\end{array}$ & $\begin{array}{r}\text { Molar } \\
\text { ratio } \\
(\mathrm{X}: 5: 1)\end{array}$ & $\% \mathrm{MG}$ & $\% \mathrm{TG}$ \\
\hline 9 & 220 & 30 & 0 & 0.02 & 94.11 \\
\hline 1 & 220 & 30 & 0 & 0.05 & 95.83 \\
\hline 34 & 220 & 30 & 0 & 0.01 & 95.80 \\
\hline 37 & 260 & 30 & 0 & 0.04 & 95.02 \\
\hline 48 & 260 & 30 & 0 & 0.00 & 98.20 \\
\hline 29 & 260 & 30 & 0 & 0.01 & 94.11 \\
\hline 21 & 220 & 150 & 0 & 0.42 & 94.72 \\
\hline 2 & 220 & 150 & 0 & 0.13 & 98.08 \\
\hline 47 & 220 & 150 & 0 & 0.19 & 95.94 \\
\hline $16^{\mathrm{a}}$ & 260 & 150 & 0 & 54.72 & 23.97 \\
\hline $30^{\mathrm{a}}$ & 260 & 150 & 0 & 51.12 & 24.09 \\
\hline $22^{a}$ & 260 & 150 & 0 & 54.31 & 22.60 \\
\hline 14 & 220 & 30 & 30 & 0.00 & 93.01 \\
\hline 26 & 220 & 30 & 30 & 0.00 & 94.21 \\
\hline 17 & 220 & 30 & 30 & 0.00 & 96.15 \\
\hline 6 & 260 & 30 & 30 & 0.16 & 76.40 \\
\hline 7 & 260 & 30 & 30 & 0.11 & 83.51 \\
\hline 39 & 260 & 30 & 30 & 0.31 & 76.15 \\
\hline 35 & 220 & 150 & 30 & 0.02 & 93.96 \\
\hline 42 & 220 & 150 & 30 & 0.92 & 82.85 \\
\hline 38 & 220 & 150 & 30 & 0.04 & 77.89 \\
\hline 33 & 260 & 150 & 30 & 37.30 & 13.82 \\
\hline 25 & 260 & 150 & 30 & 37.37 & 24.05 \\
\hline 12 & 260 & 150 & 30 & 37.77 & 14.06 \\
\hline 24 & 220 & 90 & 15 & 0.02 & 93.32 \\
\hline 46 & 220 & 90 & 15 & 0.07 & 86.96 \\
\hline 11 & 220 & 90 & 15 & 0.69 & 84.83 \\
\hline 23 & 260 & 90 & 15 & 11.77 & 62.34 \\
\hline 15 & 260 & 90 & 15 & 13.65 & 59.85 \\
\hline 45 & 260 & 90 & 15 & 14.53 & 56.58 \\
\hline 4 & 240 & 30 & 15 & 0.00 & 91.94 \\
\hline 18 & 240 & 30 & 15 & 0.00 & 92.55 \\
\hline 10 & 240 & 30 & 15 & 0.00 & 97.41 \\
\hline 5 & 240 & 150 & 15 & 30.85 & 37.41 \\
\hline 20 & 240 & 150 & 15 & 31.82 & 53.73 \\
\hline 19 & 240 & 150 & 15 & 28.65 & 56.85 \\
\hline 40 & 240 & 90 & 0 & 1.11 & 94.42 \\
\hline 8 & 240 & 90 & 0 & 0.72 & 91.54 \\
\hline 36 & 240 & 90 & 0 & 1.30 & 88.67 \\
\hline 13 & 240 & 90 & 30 & 4.19 & 81.40 \\
\hline 44 & 240 & 90 & 30 & 3.17 & 88.61 \\
\hline 27 & 240 & 90 & 30 & 3.55 & 76.38 \\
\hline 43 & 240 & 90 & 15 & 4.95 & 68.81 \\
\hline 32 & 240 & 90 & 15 & 5.54 & 69.80 \\
\hline 28 & 240 & 90 & 15 & 7.08 & 74.41 \\
\hline 31 & 240 & 90 & 15 & 6.55 & 57.42 \\
\hline 41 & 240 & 90 & 15 & 3.24 & 69.99 \\
\hline 3 & 240 & 90 & 15 & 6.60 & 78.66 \\
\hline
\end{tabular}




\section{घG conversion $\square$ MG Yield $\square$ DG Yield}

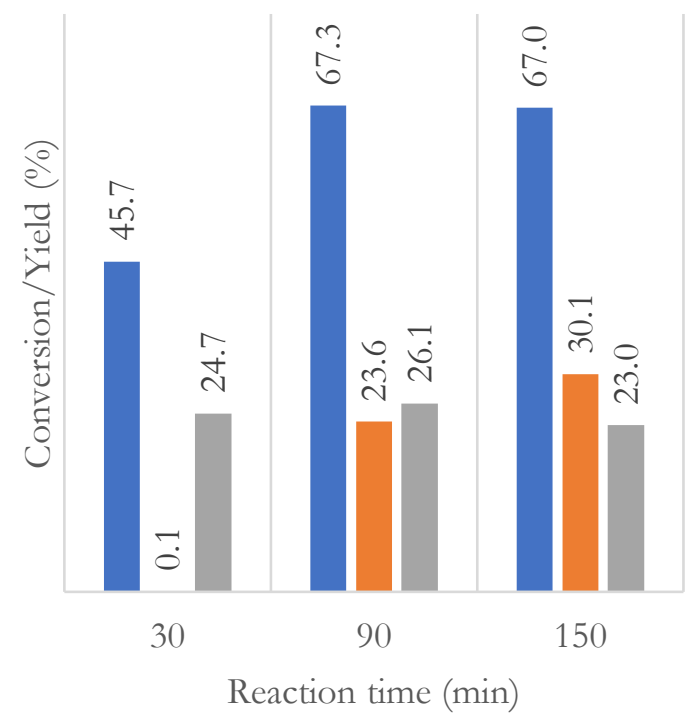

Fig. 3. Effect of reaction time on glycerolysis of palm oil at $260{ }^{\circ} \mathrm{C}$ at $60 \%$ reactor loading, molar ratio of oil to glycerol to isopropanol (1:5:15).

To enhance the triglyceride conversion, increasing of temperature was generally employed in the non-catalytic process. However, the excess temperature could promote thermal degradation of triglyceride and glycerol. It was reported that thermal degradation of triglyceride takes place at $280^{\circ} \mathrm{C}$. The products of the degradation reaction are small molecules of fatty acids [15]. Those products could contaminate in the glycerolysis reaction because the fatty acids are the intermediate of this reaction [3]. For glycerol, the degradation temperature is approximately $250-300{ }^{\circ} \mathrm{C}$ depending on the reaction time. The products of glycerol degradation are water and acrolein that formed by ionic and radical reactions. When the reaction is prolonged or the temperature is enhanced, the acrolein could decompose to acrylic acid, acrylamide, and polyarolein [16]. Therefore, the maximum reaction temperature in this study is limited at $260^{\circ} \mathrm{C}$.

\subsection{Effects of Reactor Loading}

To comparison of the MG yield obtained from $40 \%$ to $80 \%$ reactor loading, the molar ratio of palm oil to glycerol to isopropanol was fixed at 1:5:15. The results are depicted in Fig 4. The glycerolysis reaction with a low reactor loading $(40 \%)$ gave a higher glycerol conversion when compared to $60 \%$ and $80 \%$ reactor loading. A $37.4 \%$ of MG yield was observed when the reactor loading is $40 \%$; whereas the MG yield decreased to $28.6 \%$ when use the $80 \%$ of reactor loading in 150 minutes of reaction time.

The drawing of the reactants in a tube batch reactor is shown in Fig. 5. The minimal head free space suggests that a small volume of isopropanol could be vaporized to reside in their space. The added isopropanol is mostly relied on the liquid phase of the mixture reactants during the reaction. When increasing of reactor loading at a same molar ratio (oil: glycerol: isopropanol $=1: 5: 15$ ), the head free space was decreased; thus, less isopropanol can vaporize into head free space.

Likewise, the effects of dilution of the reactants is due to excess amount of isopropanol in reactor. The isopropanol molecule could obstruct the reaction between triglyceride and glycerol. Furthermore, the isopropanol is reactive at supercritical condition. Consequently, the transesterification of triglyceride and isopropanol could take place [17]. The GC-MS analysis was preformed to proof this hypothesis as shown in Section 3.5.

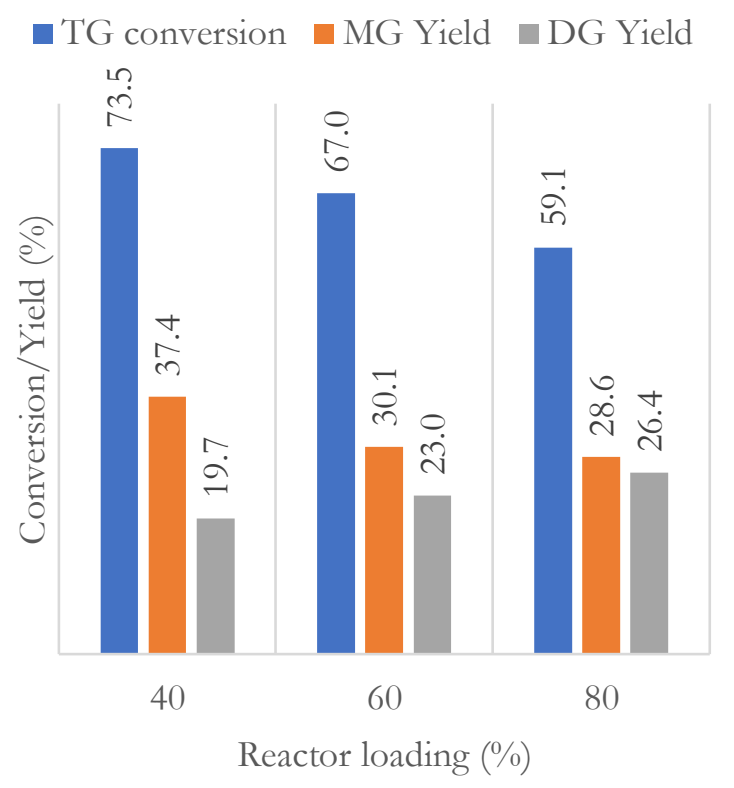

Fig. 4. Effect of reaction time on glycerolysis of palm oil at $260{ }^{\circ} \mathrm{C}, 150 \mathrm{~min}$. Molar ratio of oil to glycerol to isopropanol (1:5:15).

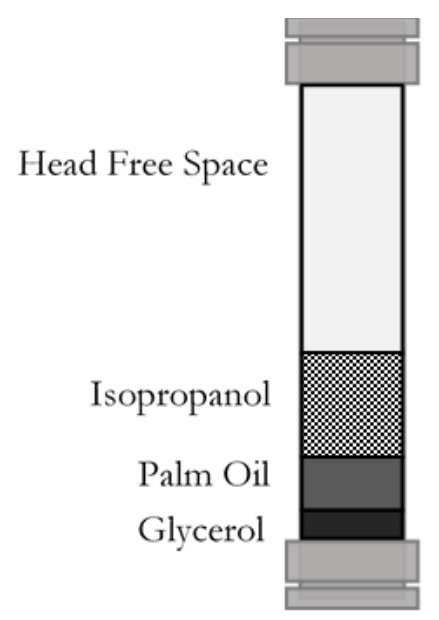

Fig. 5. The Proportion of reactants in a tube batch reactor at ambient conditions. 


\subsection{Effect of Isopropanol Addition}

In this section, the experiments were studied by reactor loading to $60 \%$ using a palm oil to glycerol molar ratio of 1:5 and vary molar ratios of isopropanol from 0 30 with 150 minutes of reaction time. The results are illustrated in Fig. 6. After reaction complete, the $30.1 \%$ of a MG yield was observed at molar ratio of palm oil: glycerol: isopropanol of 1:5:15. The reaction without adding of isopropanol shown the lowest MG yield $(0.3 \%)$. It can be noted that the addition of isopropanol resulted in significant increase in glycerol conversion. The presence of isopropanol, which exists as vapor within head free space of the reactor enhances the pressure in the reactor and improving the MG yield.

To understand the effect of isopropanol addition on glycerol conversion, the molar ratio of palm oil: glycerol: isopropanol was increased to 1:5:30 with 150 minutes of reaction time. The results are presented in Fig. 6. When amount of isopropanol is increased, the amounts of glycerol and palm oil that could be load to the reactor decreases resulting in the dilution of glycerol and palm oil in the reaction thus decreasing the MG yield (21.1\%). Moreover, the transesterification of isopropanol and palm oil could occur as mention in Section 3.2.

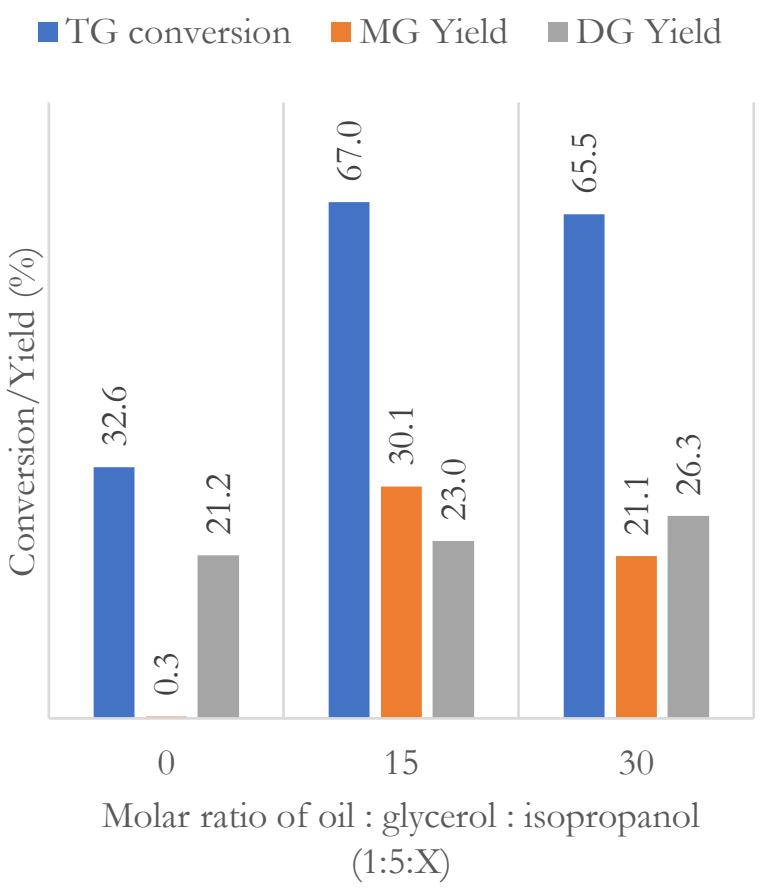

Fig. 6. Effect of isopropanol addition on glycerolysis of palm oil at $260{ }^{\circ} \mathrm{C}, 150 \mathrm{~min}$ and $60 \%$ reactor loading. Molar ratio of oil to glycerol to isopropanol (1:5:X).

\subsection{Analysis of Variance and Regression Model}

The experimental results (Table 3) were subjected to an analysis of variance (ANOVA). From this analysis, an ANOVA table was obtained for each output as a response variable: monoglyceride $(\% \mathrm{MG})$ and triglyceride $(\% \mathrm{TG})$ contents. The ANOVAs employing $\% \mathrm{MG}$ and $\% \mathrm{TG}$ as the response variable yielded statistically meaningful regression models, which are shown in Eq. (3) and (4), respectively:

$$
\begin{aligned}
& \% \mathrm{MG}=6.21+10.32 \mathrm{~A}+12.13 \mathrm{~B}-1.27 \mathrm{C}+11.22 \mathrm{AB}- \\
& 1.93 \mathrm{AC}-1.95 \mathrm{BC}+9.04 \mathrm{~B}^{2}-3.84 \mathrm{C}^{2} \\
& \% \mathrm{TG}=74.18-17.78 \mathrm{~A}-18.03 \mathrm{~B}-5.14 \mathrm{C}-14.81 \mathrm{AB}-7.07 \mathrm{~B}^{2} \\
& +8.11 \mathrm{C}^{2}
\end{aligned}
$$

where A represents temperature, B represents reaction duration, and $C$ represents the molar ratio of IPA to palm oil. All parameters are in coded unit.

The coefficients of determination $\left(\mathrm{R}^{2}\right)$ of Eq. (3) and (4) are 0.97 and 0.94 , respectively, both quite high. It is clear from the results in Tables 4 and 5 that temperature's effect (A) is slightly weaker than that of reaction duration (B). For both $\% \mathrm{MG}$ and $\% \mathrm{TG}$ analyses, the molar ratio of IPA to palm oil shows the weakest effect (C) of the three effects. In Eq. (3), the negative signs on the coefficients of all three of these effects indicate that \%TG is reduced when any of these factors is increased.

The ANOVA tables for $\% \mathrm{MG}$ and $\% \mathrm{TG}$ are provided in Tables 4 and 5, respectively. It should be noted that for a statistical significance level of $p<0.01$, the molar ratio of IPA to palm oil shows a significant effect on $\%$ TG but an insignificant effect on \%MG.

Table 4. Analysis of variance (ANOVA) employing monoglyceride as response.

\begin{tabular}{crrrrr}
\hline Source & $\begin{array}{r}\text { Sum of } \\
\text { Squares }\end{array}$ & df & $\begin{array}{r}\text { Mean } \\
\text { Square }\end{array}$ & $\begin{array}{r}\text { F } \\
\text { Value }\end{array}$ & p-Value \\
\hline Model & 11576.72 & 8 & 1447.09 & 160.86 & $<0.0001$ \\
A & 3193.43 & 1 & 3193.43 & 354.99 & $<0.0001$ \\
B & 4412.85 & 1 & 4412.85 & 490.54 & $<0.0001$ \\
C & 48.57 & 1 & 48.57 & 5.40 & 0.0255 \\
AB & 3020.72 & 1 & 3020.72 & 335.79 & $<0.0001$ \\
AC & 89.17 & 1 & 89.17 & 9.91 & 0.0031 \\
BC & 91.52 & 1 & 91.52 & 10.17 & 0.0028 \\
B & 718.87 & 1 & 718.87 & 79.91 & $<0.0001$ \\
C & 129.81 & 1 & 129.81 & 14.43 & 0.0005 \\
Residual & 350.84 & 39 & 9.00 & & \\
Lack of & 326.81 & 6 & 54.47 & 74.79 & $<0.0001$ \\
Fit & & & & & \\
Pure & 24.03 & 33 & 0.73 & & \\
Error & & & & & \\
Core & 11927.57 & 47 & & & \\
Total & & & & &
\end{tabular}

However, for products obtained from the reaction at optimal conditions of $260{ }^{\circ} \mathrm{C}$ and $150 \mathrm{~min}$, the $\% \mathrm{MG}$ values achieved in the solvent-free process (runs 16, 30, and 22) are approximately 15\% higher than those achieved in the IPA-added process (runs 33, 25, and 12). For comparison, the glycerolysis of triolein in a non-catalytic, solvent-free system has been reported to yield a monoglyceride content of $44.45 \pm 0.35 \%$ [3] 
The maximum monoglyceride content $(\% \mathrm{MG})$ was observed at the highest measured levels of temperature and reaction duration. At these levels, the triglyceride content $(\% \mathrm{TG})$ was approximately $20 \%$. Further increase in temperature is not suitable because triglyceride is prone to decompose at $280{ }^{\circ} \mathrm{C}$. Furthermore, extending the reaction duration to $180 \mathrm{~min}$ did not significantly enhance the \%MG. Furthermore, at this duration the \%TG fell below $20 \%$, indicating triglyceride degradation. Therefore, the maximum reaction temperature and duration were limited at $260^{\circ} \mathrm{C}$ and $150 \mathrm{~min}$, respectively.

Table 5. Analysis of variance (ANOVA) employing triglyceride as response.

\begin{tabular}{crrrrr}
\hline Source & $\begin{array}{r}\text { Sum of } \\
\text { Squares }\end{array}$ & df & $\begin{array}{r}\text { Mean } \\
\text { Square }\end{array}$ & $\begin{array}{r}\mathrm{F} \\
\text { Value }\end{array}$ & $\begin{array}{r}\mathrm{p}- \\
\text { Value }\end{array}$ \\
\hline Model & 25989.81 & 6 & 4331.64 & 100.60 & $<$ \\
$\mathrm{A}$ & 9480.31 & 1 & 9480.31 & 220.17 & 0.0001 \\
& & & & & 0.0001 \\
$\mathrm{~B}$ & 9749.18 & 1 & 9749.18 & 226.41 & $<$ \\
& & & & & 0.0001 \\
$\mathrm{C}$ & 792.86 & 1 & 792.86 & 18.41 & 0.0001 \\
$\mathrm{AB}$ & 5266.69 & 1 & 5266.69 & 122.31 & $<$ \\
& & & & & 0.0001 \\
$\mathrm{~B}^{2}$ & 440.32 & 1 & 440.32 & 10.23 & 0.0027 \\
$\mathrm{C}^{2}$ & 579.17 & 1 & 579.17 & 13.45 & 0.0007 \\
Residual & 1765.43 & 41 & 43.06 & & \\
Lack of & 832.42 & 8 & 104.05 & 3.68 & 0.0036 \\
Fit & & & & & \\
Pure & 933.01 & 33 & 28.27 & & \\
$\begin{array}{c}\text { Error } \\
\text { Core }\end{array}$ & 27755.25 & 47 & & & \\
Total & & & & & \\
\hline
\end{tabular}

\subsection{GC-MS analysis}

The addition of isopropanol can reduce the viscosity of reaction mixture for the continuous process, but the exceeding amount of isopropanol reduces the \%MG and generates the fatty acid propyl esters as notice by GC-MS analysis as shown in Fig. 7. It is clear that the reaction product obtained at a reaction temperature of $260{ }^{\circ} \mathrm{C}$, a molar ratio of glycerol to palm oil of 5:1, a molar ratio of isopropanol to palm oil of 30:1 contaminates by isopropyl fatty acid esters.

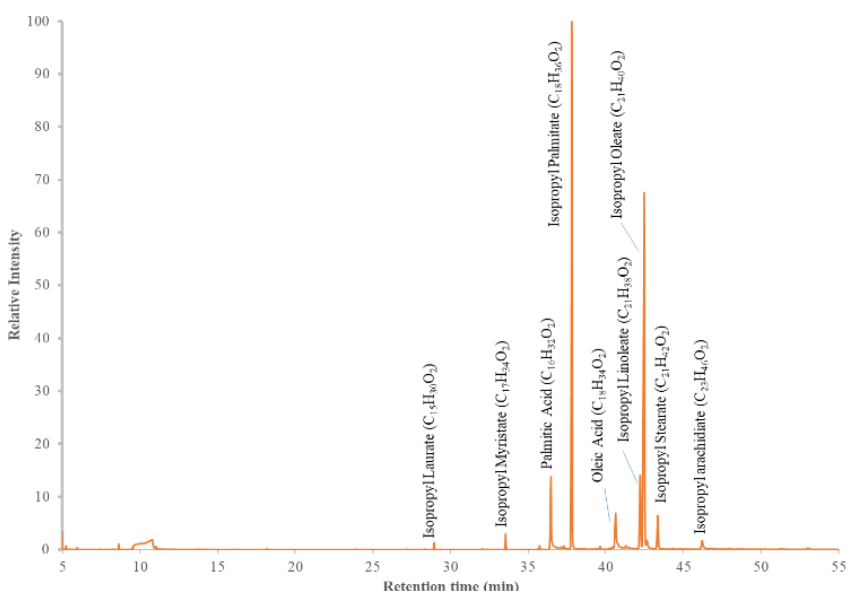

Fig. 7. Chromatogram of product obtained at a reaction temperature of $260{ }^{\circ} \mathrm{C}$, a molar ratio of glycerol to palm oil of 5:1, a molar ratio of isopropanol to palm oil of 30:1, and a reaction duration of $150 \mathrm{~min}$.

However, even product obtained using the isopropanol added process is probably suitable for biolubricant applications because it contains the isopropyl fatty acid esters [19]. In the isopropanol added process, palm oil as a feedstock yields a lower \%MG than triolein is cited in the literature as yielding. This is probably because of the effects of saturated FAs (palmitic and stearic acids) in palm oil.

\subsection{Preliminary Study of Monoglyceride Production with Crude Glycerol}

After the optimal condition for monoglyceride production by pure glycerol was obtained, the crude glycerol was employed as raw material. The properties crude glycerol is shown in Table 6 .

Table 6. Properties of crude glycerol obtained biodiesel production plant.

\begin{tabular}{|c|c|c|c|}
\hline Property & $\begin{array}{l}\text { Testing } \\
\text { method }\end{array}$ & Limit & Value \\
\hline $\begin{array}{l}\text { Glycerol content } \\
\text { (\%wt.) }\end{array}$ & $\begin{array}{l}\text { BS } 5711 \text { part } \\
3: 1979\end{array}$ & $\begin{array}{l}80 \\
\text { Min. }\end{array}$ & 80.82 \\
\hline $\begin{array}{l}\text { Water content } \\
\text { (\%wt.) }\end{array}$ & $\begin{array}{l}\text { ISO 2097- } \\
1972\end{array}$ & - & 13.44 \\
\hline $\begin{array}{l}\text { Methanol } \\
\text { content (\%wt.) }\end{array}$ & $\begin{array}{l}\text { BS } 5711 \text { part } \\
11: 1979\end{array}$ & $\begin{array}{l}0.5 \\
\text { Max. }\end{array}$ & 0.007 \\
\hline Density at $30^{\circ} \mathrm{C}$ & $\begin{array}{l}\text { Digital Density } \\
\text { Meter }\end{array}$ & - & 1.25 \\
\hline Salt content & $\begin{array}{l}\text { BS } 5711 \text { part } \\
\text { 12: } 1979\end{array}$ & 7 Max. & 3.58 \\
\hline Ash content & $\begin{array}{l}\text { ISO 2098- } \\
1972\end{array}$ & - & 1.05 \\
\hline MONG a & $\begin{array}{l}\text { ISO } 2464- \\
1973\end{array}$ & - & 1.10 \\
\hline $\mathrm{pH}$ & & - & 5.78 \\
\hline
\end{tabular}


The crude glycerol has the water content of $13.44 \%$ wt. and the glycerol content of $80.82 \%$ wt. Thus, the lower \%MG in the product could be expected. Furthermore, the crude glycerol contaminates with $0.007 \%$ wt. of methanol. The formation of methyl ester could occur because the reaction temperature is higher than critical temperature of methanol. The density of crude glycerol is slightly higher than that of $99 \%$ pure glycerol $\left(1.26 \mathrm{~g} / \mathrm{cm}^{3}\right)$. In Bangchak Biofuel Co., Ltd., the salts in crude glycerol becomes from the alkaline catalyst and neutralization acid which are $\mathrm{KOH}$ and $\mathrm{H}_{3} \mathrm{PO}_{4}$, respectively. After complete combustion, the ash could be used as the fertilizer because it consists of $\mathrm{K}_{2} \mathrm{PO}_{3}$. The monoglyceride non-glycerol (MONG) is calculated from 100 subtract by the summation of glycerol, water, methanol, salt, and ash contents. The reaction product obtained from crude glycerol is revealed in Fig. 7.

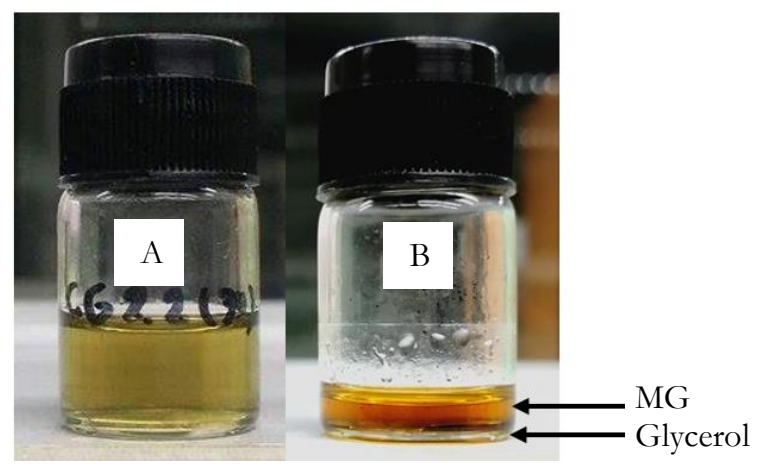

Fig. 7. The reaction products obtained at a reaction temperature of $260{ }^{\circ} \mathrm{C}$, a molar ratio of glycerol to palm oil of 5:1, a molar ratio of isopropanol to palm oil of $30: 1$, and a reaction duration of $150 \mathrm{~min}(\mathrm{~A})$ product obtained from the complete reaction, and (B) product after isopropanol was evaporated.

At reaction temperature of $260{ }^{\circ} \mathrm{C}$, molar ratio between palm oil to glycerol of 1:5, and reaction time of $150 \mathrm{~min}$, the $\% \mathrm{MG}$ obtained from pure glycerol was $53.03 \%$ while the $\% \mathrm{MG}$ of $46.58 \%$ was observed when using crude glycerol as reactant. The product was contaminated by $0.5 \%$ wt. of fatty acid methyl esters. The effects of water in crude glycerol would be investigated in the further study.

\section{Conclusion}

Isopropanol has been shown as an effective solvent for the glycerolysis of palm oil. The isopropanol addition and reactor loading are the parameters that affecting to glycerol conversion. The optimal conditions were set as $260{ }^{\circ} \mathrm{C}$ in 150 minutes and $60 \%$ reactor loading, giving the highest monoglyceride yield $(37.4 \%)$. The molar ratio of glycerol to palm oil to isopropanol is 5:1:15, respectively. Furthermore, the IPA-added process generated $<10 \%$ FA propyl esters when conducted at optimal temperature and duration $\left(260^{\circ} \mathrm{C}\right.$ and $\left.150 \mathrm{~min}\right)$. Temperature and reaction duration show significant effects on monoglyceride content (\%MG) and triglyceride content (\%TG), while the ratio of isopropanol (IPA) to palm oil shows the weakest influence on $\% \mathrm{MG}$ and $\% \mathrm{TG}$. Monoglyceride yield is approximately 15\% higher in the solvent-free process than in the IPA-added process. Furthermore, the IPA-added process generated $<10 \% \mathrm{FA}$ propyl esters when conducted at optimal temperature and duration $\left(260^{\circ} \mathrm{C}\right.$ and $\left.150 \mathrm{~min}\right)$.

\section{Acknowledgement}

The authors would like to acknowledge all supports from Chulalongkorn University, Faculty of Science, Department of Chemical Technology, Office of Academic Affairs, Chulalongkorn University, and PETROMAT for financial support.

\section{References}

[1] M. R. Monteiro, C. L. Kugelmeier, R. S. Pinheiro, M. O. Batalha, and A. D. S. César, "Glycerol from biodiesel production: Technological paths for sustainability," Renewable and Sustainable Energy Reviews, vol. 88, pp. 109-122, 2018.

[2] Y. Zheng, X. Chen, and Y. Shen, "Commodity chemicals derived from glycerol, an important biorefinery feedstock," Chemical Reviews, vol. 108, 2008.

[3] Q. Liu, T. Yan, Z. Jiang, and T. Fang, "Sustainable utilization of crude glycerol from biodiesel production: Catalyst free monoacyglycerols production," Journal of Chemical Technology \& Biotechnology, vol. 92, pp. 1801-1808, 2017.

[4] A. W. Go, S. Sutanto, S. Ismadji, and Y.-H. Ju, "Catalyst free production of partial glycerides: Acetone as solvent," RSC Advances, vol. 5, pp. 3083330840, 2015.

[5] A. K. Singh and M. Mukhopadhyay, "Lipasecatalyzed glycerolysis of olive oil in organic solvent medium: Optimization using response surface methodology," Korean Journal of Chemical Engineering, vol. 33, pp. 1247-1254, 2016.

[6] H. P. Tai and G. Brunner, "Mono- and diacylglycerol synthesis in $\mathrm{CO}_{2}$-expanded acetone," The Journal of Supercritical Fluids, vol. 59, pp. 87-91, 2011.

[7] H. Luo et al., "Monoacylglycerol synthesis by glycerolysis of soybean oil using alkaline ionic liquid," Industrial \&o Engineering Chemistry Research, vol. 54, pp. 4923-4928, 2015.

[8] H. R. Ong, M. M. R. Khan, R. Ramli, R. M. Yunus, and M. W. Rahman, "Glycerolysis of palm oil using copper oxide nanoparticles combined with homogeneous base catalyst," New Journal of Chemistry, vol. 40, pp. 8704-8709, 2016.

[9] C. A. Ferretti, A. Soldano, C. R. Apesteguía, and J. I. Di Cosimo, "Monoglyceride synthesis by glycerolysis of methyl oleate on solid acid-base catalysts," 
Chemical Engineering Journal, vol. 161, pp. 346-354, 2010.

[10] P. H. L. Moquin, F. Temelli, H. Sovová, and M. D. A. Saldaña, "Kinetic modeling of glycerolysishydrolysis of canola oil in supercritical carbon dioxide media using equilibrium data," The Journal of Supercritical Fluids, vol. 37, pp. 417-424, 2006.

[11] F. Qin, B. Nohair, W. Shen, H. Xu, and S. Kaliaguine, "Promotional effects of $\mathrm{CeO}_{2}$ on stability and activity of $\mathrm{CaO}$ for the glycerolysis of triglycerides, Catalysis Letters, vol. 146, pp. 1273-1282, 2016.

[12] W. Sakdasri, R. Sawangkeaw, and S. Ngamprasertsith, "An entirely renewable biofuel production from used palm oil with supercritical ethanol at low molar ratio," Brazilian Journal of Chemical Engineering, vol. 34, pp. 1023-1034, 2017.

[13] W. Sakdasri, R. Sawangkeaw, and S. Ngamprasertsith, "Response surface methodology for the optimization of biofuel production at a low molar ratio of supercritical methanol to used palm olein oil," Asia-Pacific Journal of Chemical Engineering, vol. 11, pp. 539-548, 2016.

[14] P. H. L. Moquin, F. Temelli, H. Sovová, and M. D. A. Saldaña, "Kinetic modeling of glycerolysis- hydrolysis of canola oil in supercritical carbon dioxide media using equilibrium data," The Journal of Supercritical Fluids, vol. 37, pp. 417-424, 2006.

[15] S. Ngamprasertsith, C. E. Laetoheem, and R. Sawangkeaw, "Continuous production of biodiesel in supercritical ethanol: A comparative study between refined and used palm olein oils as feedstocks," Jorunal of Brazilian Chemical Society, vol. 25, pp. 1746-1753, 2014.

[16] L. Qadariyah et al., "Degradation of glycerol using hydrothermal process," Bioresource Technology, vol. 102, pp. 9267-9271, 2011.

[17] O. Farobie, Z. Y. M. Leow, T. Samanmulya, and Y. Matsumura, "New insights in biodiesel production using supercritical 1-propanol," Energy Conversion and Management, vol. 124, pp. 212-218, 2016.

[18] D. Montgomery, Design and Analysis of Experiments, 7th ed. New York, USA: John Wiley and Sons, 2010.

[19] L. A. Quinchia, M. A. Delgado, C. Valencia, J. M. Franco, and C. Gallegos, "Natural and synthetic antioxidant additives for improving the performance of new biolubricant formulations," Journal of Agricultural and Food Chemistry, vol. 59, pp. 1291712924, 2011. 


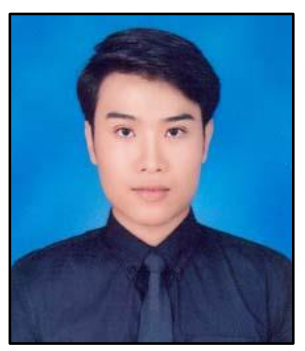

Ittirit Phichaion was born in Lampang province, Thailand in 1994. He received the B.S. degrees in department of chemistry, faculty of Science from Chiang Mai University, Chiang Mai, Thailand in 2016.

From 2015 to 2016, he was a student with the Physical Chemistry in Computational Laboratory. Since 2017, he decided to study at the Chemical Technology Department, Faculty of Science, Chulalongkorn University, Bangkok, Thailand.

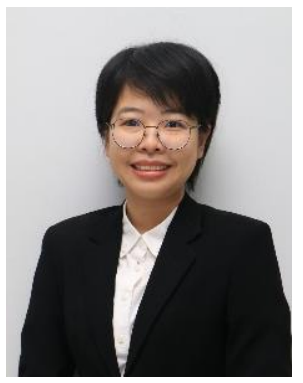

Winatta Sakdasri was born in Nan, Thailand in 1987. She received the B.S. degree in Department of industrial chemistry, Faculty of Science, from Chiang Mai University, Thailand, in 2010. She received a Ph.D. degree in Chemical technology, Faculty of Science, from Chulalongkorn University, Thailand, in 2016,

From 2019 to present, she is a lecturer at Faculty of Food-industry, King Mongkut's Institute of Technology Ladkrabang, Bangkok, Thailand. Her research interests in Supercritical $\mathrm{CO}_{2}$ extraction, value added product from biomass, Techno-economic analysis, and Biofuel production in supercritical alcohols.

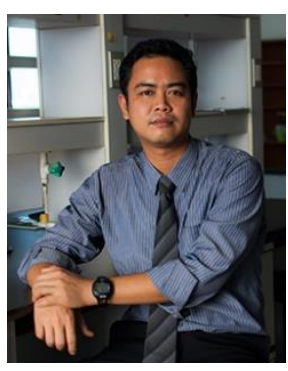

Ruengwit Sawangkeaw was born in Lopburi, Thailand in 1981. He received the bachelor's degree in Science from The Department of Industrial Chemistry, Faculty of Applied Science, King Mongkut's University of Technology North Bangkok, Thailand in 2002. He received the master's degree in Science and Doctorate in Science, in 2005 and 2010, respectively from Department of Chemical Technology, Faculty of Science, Chulalongkorn University, Thailand.

From 2010 to 2012, he worked at Fuels Research Center, Department of Chemical Technology, Chulalongkorn University, Thailand as the post-doctoral researcher. He studied on Production and Life Cycle Assessment (LCA) study of biofuels production from low-temperature pyrolysis of vegetable oils in supercritical alcohols. From 2012 to present, he is a researcher at The Institute of Biotechnology and Genetic Engineering, Chulalongkorn University. His research interests in Biofuels production via supercritical fluids, Pretreatment of lignocellulosic biomass, Supercritical fluids extraction, Subcritical water reactive extraction, and Valorization of agricultural wastes via thermo- and bioconversion processes.

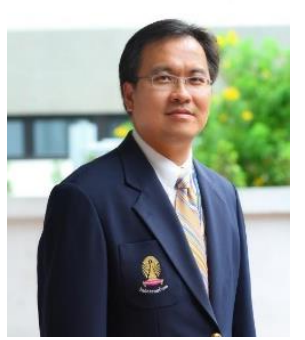

Professor Somkiat Ngamprasertsith was born in Lopburi, Thailand in 1965. He received the bachelor's degree in Science from Department of Chemical Technology, Faculty of Science, Chulalongkorn University, Thailand in 1983. He received the D.E.A. in Chemical engineering and Doctorate in Process Engineering, in 1989 and 1993, respectively from Institut National Polytechnique de Toulouse, France.

From 1993 to present, he worked at Fuels Research Center, Department of Chemical Technology, Faculty of Science, Chulalongkorn University, Thailand. His research interests in Biofuels production via supercritical fluids, Pretreatment of lignocellulosic biomass, Supercritical fluids extraction, Subcritical water reactive extraction, Valorization of agricultural wastes via thermo-conversion processes and Supercritical water oxidation. 